\title{
Reproductive biology of the isopod Excirolana braziliensis at the southern edge of its geographical range
}

\author{
Gastón Martínez · Omar Defeo
}

Received: 21 March 2005/Revised: 16 March 2006/ Accepted: 10 April 2006/Published online: 23 May 2006

(C) Springer-Verlag and AWI 2006

\begin{abstract}
A full analysis of the reproductive biology of the isopod Excirolana braziliensis Richardson 1912 was conducted in a sandy beach of Uruguay, located at the southernmost edge of its distributional range in the Atlantic Ocean. Reproductive and recruitment periods of $E$. braziliensis were concentrated in austral summer. Females with oostegites appeared in November, whereas total biomass, individual sizes and fecundity of ovigerous females peaked between December and January. These concurrent traits were responsible for the significant peak of juveniles in January. The size at maturity was $9.88 \mathrm{~mm}$. Four embryonic developmental stages were described and identified: mean length linearly increased from stages I to III, whereas dry weight exponentially decreased from stages I to IV. The high reproductive output $(0.41-0.58)$, reported for the first time in this isopod, exceeds the rates documented for other isopods. Reproduction of E. braziliensis at the southern edge of its range is semelparous: females produce one brood during the reproductive season, exhaust their energy reserves during incubation, and probably die at the end of the reproductive season. A macroscale comparison suggests that E. braziliensis at the southern edge of its range counteracts its narrow reproductive period by a short incubation period with
\end{abstract}

Communicated by M. Thiel

G. Martínez · O. Defeo

Facultad de Ciencias, UNDECIMAR, Iguá 4225,

P.O. Box 10773, 11400 Montevideo, Uruguay

G. Martínez $(\bowtie) \cdot$ O. Defeo

Dirección Nacional de Recursos Acuáticos,

Constituyente 1497, 11200 Montevideo, Uruguay

e-mail: gmartinez@dinara.gub.uy larger individual mature female and embryo sizes, higher fecundity and a higher percentage of ovigerous females than in subtropical and tropical populations. These extreme reproductive indicators could be attributed to the internal retention of embryos that assures offspring survival, coupled with a high adaptation capability to environmental variations across its range.

Keywords Sandy beaches - Isopods - Reproduction · Embryonic development

\section{Introduction}

Biogeographical evidence has shown sudden changes in the spatial distribution, dynamics and structure of the populations from the interior towards the periphery of a species range (Gilman 2005). At the edge of the range, populations often become more isolated and transient, also presenting a higher probability of extinction (Carter and Prince 1981; Brown et al. 1996; Kark et al. 2004). In order to identify the causes of range limits and to properly interpret the abundance distributions, one of the primary issues to be analysed is how the species behaves in terms of probability of reproductive success through one's own offspring, i.e. fitness (Hoffman and Blows 1994). This is particularly noticeable in intertidal invertebrates, where several environmental and biological factors have an outstanding role in explaining distribution ranges, as documented for rocky shores (Sagarin and Gaines 2002a, b). Surprisingly, few studies have sought to document life-history variations in sandy beach species at the edges of their distribution ranges, which have been severely undersampled (Defeo and Cardoso 2004). 
Cirolanid isopods are usually numerically dominant members of the macrofauna in exposed sandy beaches (Dahl 1952; Croacker 1967; Defeo et al. 1992, 1997). Excirolana braziliensis Richardson, 1912 (Isopoda: Cirolanidae) is a dioecious and ovoviviparous marine isopod found on Atlantic and Pacific coasts of tropical, subtropical and temperate America, from the Gulf of California to southern Chile in the Pacific and from the Gulf of Mexico to Uruguay in the Atlantic (Glynn et al. 1975; Weinberg and Starczak 1988, 1989; Defeo et al. 1992). A macroscale analysis performed by Defeo et al. (1997) showed that E. braziliensis mainly inhabits the reflective beaches in its southern end of the geographical distribution in the Atlantic Ocean with significantly coarser sand than in the rest of its distribution range, at both Pacific and Atlantic coasts, where the species inhabits dissipative or intermediate beaches with fine sand.

Recently, Cardoso and Defeo (2003) reported strong latitudinal patterns in some reproductive traits of E. braziliensis throughout its distribution range: breeding and recruitment shifted from continuous to seasonal, from tropical to temperate beaches; ovigerous females inhabiting tropical sandy beaches were smaller and became sexually mature at smaller sizes and had lower individual fecundity than in temperate beaches. Even though this work yielded a broad picture with great potential for generalization about reproductive trends on E. braziliensis, it did not provide information about the critical reproductive indicators that could only be addressed on smaller scales, notably local intra-annual trends in abundance, size at maturity, developmental stages and reproductive effort. Particularly, there are no detailed studies that quantify these indicators of reproductive performance at the edge of the species range. This has utmost importance taking into account its ovoviviparous mode of development, which tends to isolate populations (Klapow 1970; Weinberg and Starczak 1988, 1989). In this paper we conduct a full analysis of the reproductive biology of E. braziliensis in a sandy beach of Uruguay, located at the southernmost edge of its distributional range. The information gathered here, at local and intra-annual scales, is used in a macroscale comparison directed to provide additional insights about the large-scale reproductive patterns of this conspicuous isopod.

\section{Materials and methods}

The study was conducted in Arachania (34 $36^{\prime} \mathrm{S}$; $53^{\circ} 44^{\prime} \mathrm{W}$ ), an exposed microtidal (tide range $=0.5 \mathrm{~m}$ ) reflective sandy beach of Uruguay, characterised by coarse sediments (mean grain size $=0.50 \mathrm{~mm}$; sorting $=0.57 \mathrm{~mm})$, steep slope $(7.80 \%)$, and low macrofauna richness (five species: Defeo et al. 1992).

Isopods were collected during 22 consecutive months, from March 1996 through December 1997, according to a systematic sampling design. Five transects were set up perpendicular to the shoreline and separated by $8 \mathrm{~m}$. Sampling units (SUs) on each transect were done every $4 \mathrm{~m}$ with a sheet metal cylinder, $27 \mathrm{~cm}$ in diameter and $40 \mathrm{~cm}$ deep, from the base of the dunes to the seaward limit of the isopod distribution, until at least two consecutive SUs yielded no isopods. More than 75 SUs were taken during each month. The organisms retained after sieving through a $0.5-\mathrm{mm}$ mesh were fixed in $5 \%$ buffered formalin. For most samples, the coarse sand required that organisms were separated from the sand by careful sorting in the laboratory. Isopods were measured to the nearest $0.1 \mathrm{~mm}$ from the tip of the cephalon to the end of the telson (Dexter 1977), dried at $60^{\circ} \mathrm{C}$ for $24 \mathrm{~h}$ and weighed (dry weight) to the nearest $0.0001 \mathrm{~g}$.

Isopods were classified as juveniles (sizes up to $4 \mathrm{~mm}$ and with no visible sexual characteristics) and adults (sizes $>4 \mathrm{~mm}$, categorized as males, females and ovigerous females with eggs or embryos). Males were recognized by the paired penes on the sternum of the seventh thoracic segment and the stylets on the second pleopod. Females have no recognizable sexual characteristics (Dexter 1977). Abundance of ovigerous females and juveniles was estimated as biomass per strip transect (BST, in $\mathrm{g} \mathrm{m}^{-1}$ : Defeo 1998) and compared between months by a one-way analysis of variance (ANOVA). BST estimates of juveniles were transformed $\left(\mathrm{Y}^{1 / 4}\right)$ in order to fulfil the requirement of homoscedasticity. When significant differences were detected, the Tukey test was applied (Zar 1999). Abundance estimates were also expressed in ind. $\mathrm{m}^{-2}$ to allow comparisons among studies.

To estimate fecundity and breeding patterns, all ovigerous females were measured and weighed, and then eggs/embryos incubated in the internal brood pouches were removed, counted and weighed. The length of ovigerous females and fecundity (embryos female ${ }^{-1}$ ) were compared between months by a oneway ANOVA, and the Tukey test for unequal sample size was used for multiple comparisons. A maturitysize relationship was built, taking into account the data obtained during the reproductive season. The estimates of the fraction of ovigerous females as a function of size were used to model the logistic maturity function and to estimate the average size at sexual maturity, as follows: 
$B_{L}=\frac{\beta}{1+\mathrm{e}^{\left(\alpha_{1}-\alpha_{2} L\right)}}$

where $B_{L}$ is the fraction of females bearing embryos in each size class $L$ and $\alpha_{1}, \alpha_{2}$ and $\beta$ are parameters. The average size at maturity $\left(L_{50 \%}\right)$ was obtained by

$L_{50 \%}=-\frac{\alpha_{1}}{\alpha_{2}}$.

The function was fitted by non-linear least squares, using the quasi-Newton algorithm.

An embryology developing sequence, using the embryos as indicators, was established according to Klapow (1970), Fish (1970) and Johnson et al. (2001). A one-way ANOVA was used to compare the total length and dry weight between stages. When significant differences were detected, the Tukey HSD test was applied (Zar 1999). Reproductive output was estimated as the ratio between the dry mass of embryos and the dry mass of each female (Harper and Ogden 1970), and a one-way ANOVA was conducted to detect differences between months within the reproductive season.

\section{Results}

Reproductive activity of E. braziliensis was totally concentrated in a narrow season comprised between December and March (austral summer), which constitute the warmest months (temperature range: 17 $23^{\circ} \mathrm{C}$ : Fig. 1 b). During this period, $14.96 \pm 1.82 \%$ (mean $\pm \mathrm{SE})$ of females were gravid. Females with oostegites appeared in November. Biomass (mean $\pm \mathrm{SE}$ ) of ovigerous females peaked in January $\left(1.86 \pm 0.63 \mathrm{~g} \mathrm{~m}^{-1}\right.$, equivalent to $20.60 \pm 1.86$ ind. $\mathrm{m}^{-2}$ : Fig. 1a), but no significant differences were observed between months when gravid females occurred $\left(F_{4,20}=0.54 ; P=0.71\right)$. Following the same intra-annual pattern, juveniles were mainly found between January and March (Fig. 1a), peaking in January 1997 $\left(0.96 \pm 0.38 \mathrm{~g} \mathrm{~m}^{-1}\right.$ or $214.86 \pm 126.38$ ind. $\left.\mathrm{m}^{-2}\right)$. Samples taken in January and February had significantly $\left(F_{6,28}=11.37 ; P<0.001\right)$ higher juvenile biomass than those from the remaining months (Tukey HSD test: $P=0.001)$.

The body length of ovigerous females ranged from 7.6 to $11.5 \mathrm{~mm}$, peaking in December $(10.27 \pm$ $0.27 \mathrm{~mm}$ ). Individual sizes of ovigerous females significantly differed between months $\left(F_{3,49}=6.48\right.$; $P<0.001)$, being smaller in February than in December, January and March (Tukey HSD test:
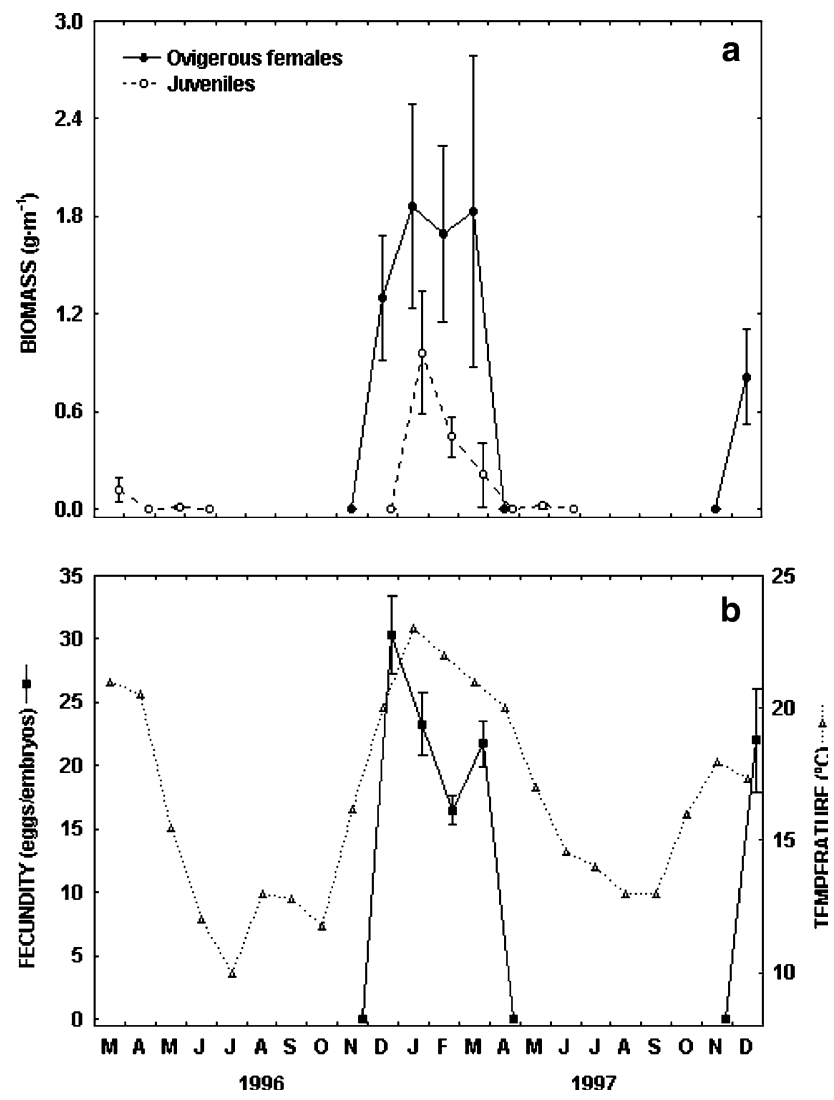

Fig. 1 E. braziliensis. Monthly variations (mean $\pm \mathrm{SE}$ ) in: a biomass $\left(\mathrm{g} \mathrm{m}^{-1}\right)$ of ovigerous females and juveniles; and $\mathbf{b}$ fecundity (embryos female ${ }^{-1}$ ) and temperature $\left({ }^{\circ} \mathrm{C}\right)$ in Arachania. In $\mathbf{b}$, note the different scale in the right $Y$-axis

$P=0.001$ ) (Fig. 2). Fecundity ranged between 7 and 42 embryos female $^{-1}$, peaking in December $(25 \pm 7$ embryos female ${ }^{-1}$ ) and decreasing afterwards (Fig. 1b). Significant differences were observed between months $\left(F_{3,47}=3.92 ; \quad P<0.01\right)$, with isopods in February

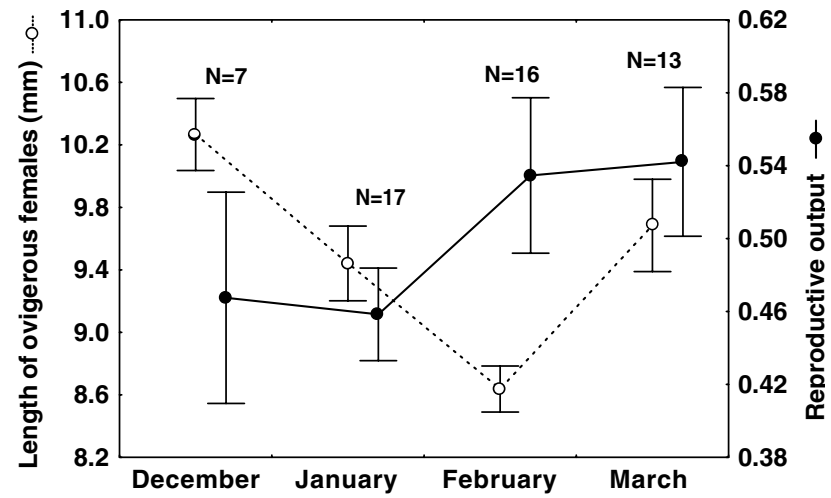

Fig. 2 E. braziliensis. Mean $( \pm \mathrm{SE})$ length $(\mathrm{mm})$ of ovigerous females and reproductive output (dry mass of embryos/dry mass of female) documented for the reproductive season comprised between December and March 
having lower fecundity than in the remaining months (Tukey HSD test: $P=0.02$ ). Isopods had no embryos from April to November, when water temperature was $<17^{\circ} \mathrm{C}$.

The progression from immaturity to maturation showed a successive increase in the proportion of mature females with size, being $100 \%$ ovigerous in the oldest length class $(12 \mathrm{~mm})$. The maturity-size relationship was explained by a 3-parameter sigmoid function given by Eq. 1 ( $\beta=0.99, \alpha_{1}=8.99, \alpha_{2}=0.91$ : $\left.R^{2}=0.90, P<0.001\right)$. The average size of females at maturity $L_{50 \%}$ (Eq. 2) was $9.88 \mathrm{~mm}$. Incubation period, estimated as the time period between first appearance of ovigerous females and juveniles, was 1 month.

Four embryonic developmental stages were described and identified for E. braziliensis (Fig. 3). (I) Ovoid fertilized eggs, with a uniformly yellow outlook. At the end of this stage, the egg membrane breaks to release the second-stage embryo. (II) Nauplius stage (sensu Johnson et al. 2001), somewhat larger and more elongated but still curved due to the embryonic membrane that maintained the embryos tightly. Morphological differentiation of the embryos has progressed such that head, thoracic and abdominal regions became distinct; however, yolk is confined primarily to the thoracic region. The biramous character of the abdominal appendages is apparent and pigmentation of the eyes has begun. (III) Between stages II and III, the embryonic cuticle ruptures and the embryo can flex its body constituting the pre-manca stage. The appendages are completely segmented, lying flat against the body and with small setae precursors arising from the cuticular surface. The segmentation of the dorsal tergites is complete. Pigmentation of the eyes appears to be uniformly black. (IV) Manca stage, indistinguishable from the first juveniles collected in
Fig. 3 E. braziliensis.

Different stages of

embryology development. a

Stage I: egg. b Stage II:

nauplius. c Stage III: pre-

manca. d Stage IV: manca
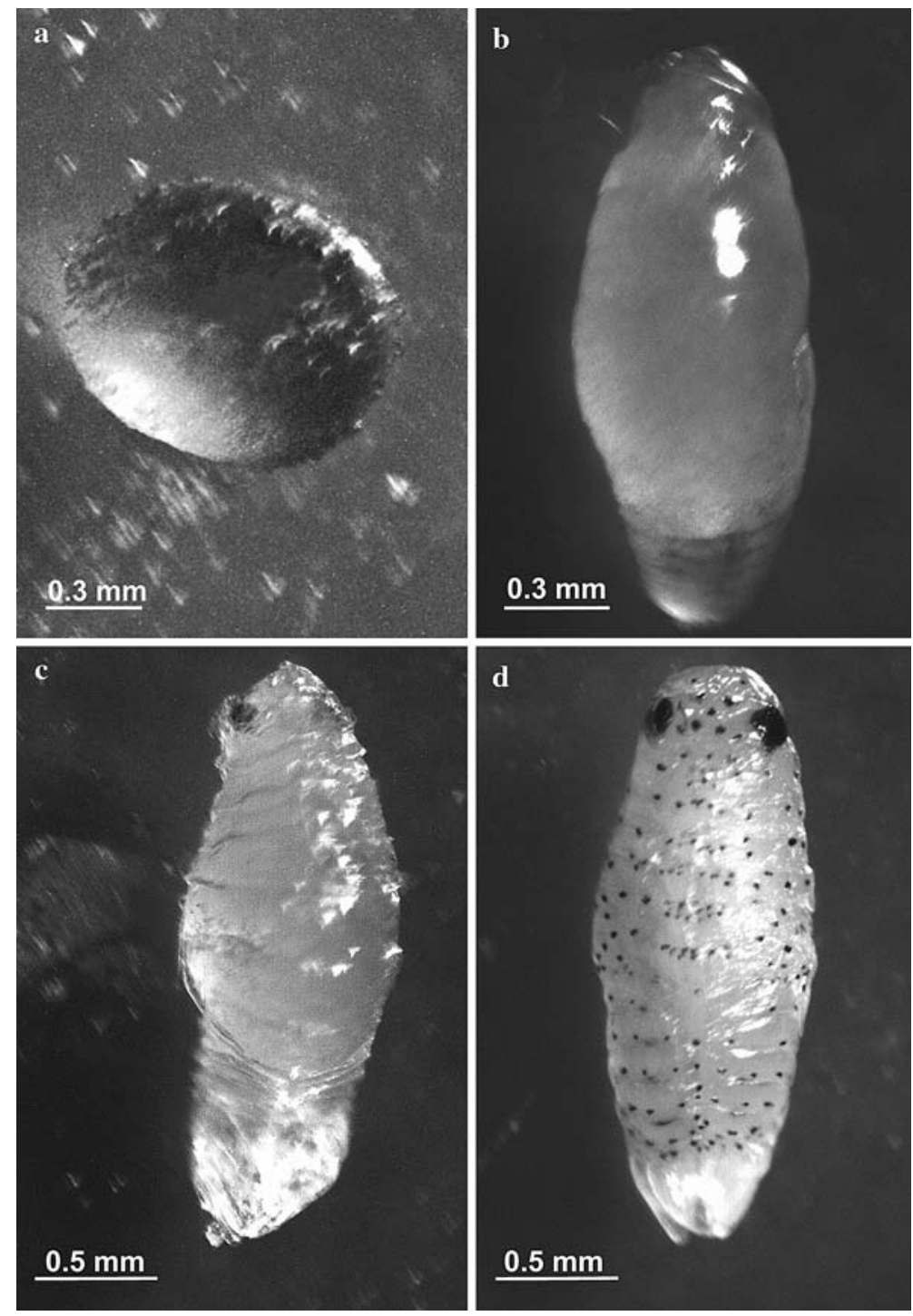
the field. Yolk material disappeared, the dorsal surface is stippled with black stellate chromatophores and setae are now visible.

The occurrence of each developmental stage showed a marked variation through time (Fig. 4). Stage I appeared only in December, whereas stage II peaked in December and January (40.0\%), thereafter decreasing to $<10.0 \%$ in February and March. Stage III showed a sustained increase from December to February, when it represented $42.1 \%$. Stage IV occurred from January to March, peaking in February (36.4\%) (Fig. 4).

Mean length during development linearly increased from stage I to stage III (Fig. 5). The total length of each embryonic developmental stage ranged as follows: $0.8-1.2 \mathrm{~mm}$ (stage I), $1.2-2.5 \mathrm{~mm}$ (stage II) and 1.9-2.8 mm (stages III and IV). Significant differences in mean length were observed between stages (ANOVA $\left.F_{3,998}=781.02, P<0.001\right)$, with stages III and IV having significantly largest sizes than stages I and II (Tukey HSD test: $P<0.01$ ). Mean dry weight for each embryo stage showed the opposite pattern, exponentially decreasing from stage I to IV (ANOVA: $F_{3,998}=13.84, P<0.001$, Fig. 5 ); stage I was heavier than the remaining ones (Tukey HSD test: $P<0.01$ ).

The reproductive output tended to show two distinct periods (Fig. 2): December-January, with a value close to 0.46 , and February-March, where the reproductive output increased by almost $20 \%$, peaking in March $(0.54 \pm 0.04)$. However, the high within-month variability precluded the detection of significant differences between months (ANOVA: $F_{3,49}=1.50$, $P=0.22$ ). The apparent increase in the reproductive output from February onwards was caused by the exponential decrease in the individual mean dry weight of females with proceeding reproductive season, from

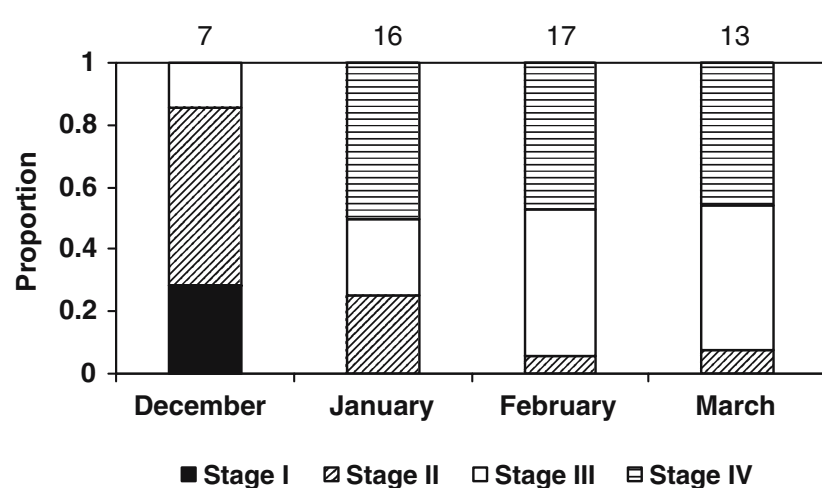

Fig. 4 E. braziliensis. Monthly variations in relative abundance of ovigerous females carrying each of the four developmental stages, for the December-March reproductive season. The total number of females examined in each month appears at the top of each column

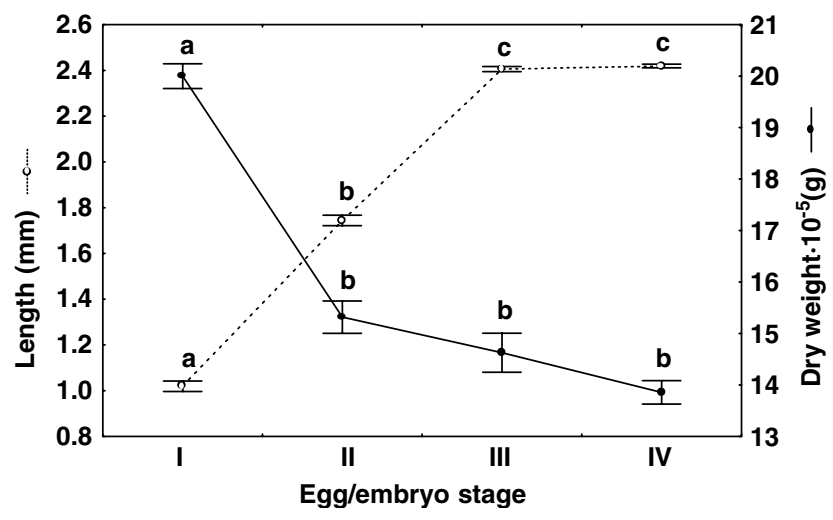

Fig. 5 E. braziliensis. Mean $( \pm \mathrm{SE})$ total length $(\mathrm{mm})$ and dry weight $(\mathrm{g})$ in each embryonic developmental stage documented for the reproductive season comprised between December and March. The number of embryos analysed for all the four stages were, respectively, 31, 235, 267 and 469. Different letters: significant differences $(P<0.01)$ in total length or dry weight between stages

$0.0108 \pm 0.0016 \mathrm{~g}$ in December to $0.0046 \pm 0.0002 \mathrm{~g}$ in February. Alternatively, the mean embryo mass showed a smooth decrease, from $0.0044 \pm 0.0005 \mathrm{~g}$ in December to $0.0025 \pm 0.0004 \mathrm{~g}$ in February. As fecundity decreased with proceeding reproductive season (Fig. 1b), individual dry weight of females and embryos decreased with proceeding developmental stage (Fig. 5), and later in the reproductive season most embryos were in advanced stages (Fig. 4); a decrease in the reproductive output was expected. However, brood biomass decreased to a lesser extent than female biomass, thus explaining the apparent increase in the reproductive output at the end of the reproductive season (Fig. 2).

\section{Discussion}

Reproductive and recruitment periods of E. braziliensis at the edge of its range were entirely concentrated during the warmest months of the year. Reproduction started in November, when females with oostegites first appeared due to the "ovigerous molt" (sensu Johnson et al. 2001), and finished in March. This narrow reproductive season contrasted with the continuous reproductive activity of this species found for tropical (Dexter 1977) and subtropical (Caetano et al. 2006) environments. Temperature could be a critical factor controlling the reproductive cycle of E. braziliensis, with a value close to $15^{\circ} \mathrm{C}$ being a threshold triggering the processes of gametogenesis and molting. Ovigerous females were firstly detected in December and juveniles in January, evidencing a shorter incubation period (1 month) than in warmer environments (Chile: 
3 months, Zúniga et al. 1985). The high percentage of gravid females throughout the 4-month reproductive season (ca. $15 \%$ per month) largely exceeded those observed in tropical beaches (ca. 2\%: Dexter 1977).

Total biomass of ovigerous females revealed fairly uniform values within the reproductive season. However, the largest individual sizes and highest fecundity of ovigerous females occurred in December/January, and explain the significant peak of juveniles in January. These trends suggest that the beginning of austral summer (December and January) is a critical reproductive/recruitment period for E. braziliensis. A largescale comparison showed that maximum total length of ovigerous females, the range estimates of fecundity (742 embryos female $\left.{ }^{-1}\right)$, size at maturity $L_{50 \%}(9.88 \mathrm{~mm})$ in Arachania, and also the relative representation of gravid females (Cardoso and Defeo 2003) are higher than those reported in subtropical (Brazil) and tropical (Panama and Peru) beaches, whereas the reverse trend are observed in total abundance (Table 1). Thus, at its southern edge of distribution, E. braziliensis counteracts the narrow duration of the breeding season and lower abundance by a high relative representation of ovigerous females with larger individual sizes and fecundity, together with a short incubation period.

The high reproductive output $(0.41-0.58)$, reported for the first time in this Pan-American beach isopod, exceeds those documented for the sympatric ovoviviparous cirolanid Excirolana armata (0.40: Lozoya and Defeo 2006) and the iteroparous terrestrial isopod Porcellio laevis (0.18: Lardies et al. 2004). Taking into account that the reproductive output represents an underestimated proxy of the reproductive effort, especially in brooding species (Fernández et al. 2000), the total proportion of energy that E. braziliensis devotes to reproduction could be also high when compared with other invertebrates (López et al. 1997; Roff 1992). The high egg production investment during the narrow reproductive season leads the species to assimilate energy as somatic production during the rest of the year, thereby delaying maturity and enhancing the reproductive output (Stearns 1976).

The four developmental stages were only observed between December and March, and their morphological characteristics roughly matched those described by Klapow (1970) for the Genus Excirolana and for E. braziliensis by Bocanegra and Oliva (1987). The developmental stages showed a marked time lag in abundance between them: stages I and II peaked in December, whereas stages III and IV peaked in February-March. Individual length of eggs/embryos clearly increased from stage I to III, and the greatest variability observed in stage II could be explained by the characteristic movement and straightening of the body observed in this stage for peracarids (Johnson et al. 2001). Mean individual size of eggs and stage IV embryos of E. braziliensis in tropical Peruvian beaches were lower than in Arachania (Table 1). The marked decrease in dry weight towards older stages could be explained by yolk consumption during embryonic development (Dworschak 1988). The opposite pattern observed between individual length and weight suggests an increase in water concentration required for solvatation, concurrently with yolk catabolism that enhances the quantity of free metabolites (Stella et al. 1996; López et al. 1997). In this sense, Klapow (1970) suggested for Excirolana chiltoni that the initial yolk material is sufficient to complete the embryonic development. The internal retention of embryos in incubating pouches could be a reproductive strategy of
Table 1 Biological attributes of different E. braziliensis populations throughout its distribution range, extracted from the following sources. Panama: Dexter (1977) and Glynn et al. (1975); Peru: Bocanegra et al. (1986) and Bocanegra and Oliva
(1987); Brazil: Fonseca et al. (2000); Chile: Zúñiga et al. (1985); Uruguay: this paper and Defeo and Martínez (2003). For Peru, only a mean estimate of surf temperature was available

\begin{tabular}{|c|c|c|c|c|c|}
\hline Population features & Panama $\left(8^{\circ} 55^{\prime} \mathrm{N}\right)$ & Peru $\left(8^{\circ} 11^{\prime} S\right)$ & Brazil $\left(23^{\circ} 02^{\prime} \mathrm{S}\right)$ & Chile $\left(23^{\circ} 27^{\prime} \mathrm{S}\right)$ & Uruguay $\left(34^{\circ} 36^{\prime} \mathrm{S}\right)$ \\
\hline Ocean & Pacific & Pacific & Atlantic & Pacific & Atlantic \\
\hline Range of surf water temperature $\left({ }^{\circ} \mathrm{C}\right)$ & $22-29$ & 17 & $20-32$ & $14-27$ & $10-23$ \\
\hline Mean density (ind. $\mathrm{m}^{-2}$ ) & 1,214 & 709 & 223 & 81 & 80 \\
\hline Ovigerous females $(\%)$ & 2 & & & & 15 \\
\hline Largest ovigerous (mm) & 4.7 & 9.1 & 8.9 & 9.0 & 11.5 \\
\hline Size range ovigerous females (mm) & $2.9-4.7$ & & $4.6-8.9$ & $4.0-9.0$ & $7.6-11.5$ \\
\hline Size at maturity $(\mathrm{mm})$ & & 5.00 & 6.90 & & 9.88 \\
\hline Reproductive season (months) & 9 & 5 & 11 & 9 & 4 \\
\hline Recruitment season (months) & 12 & 12 & 12 & 11 & 4 \\
\hline Incubation period (months) & & & & 3.0 & 1.0 \\
\hline Fecundity (no. of embryos) & $4-17$ & $11-41$ & $2-27$ & $10-27$ & $7-42$ \\
\hline Mean egg size $(\mathrm{mm})$ & & 0.78 & & & 1.02 \\
\hline Mean stage IV size (mm) & & 2.00 & & & 2.42 \\
\hline
\end{tabular}


E. braziliensis to overcome the turbulent and abrasive intertidal sandy beach environment (Klapow 1970), giving also osmotic protection (Charmantier and Charmantier-Daures 1994) and enhancing offspring survival (Thiel 2003).

Our results suggest that reproduction of E. braziliensis at the southern edge of its range is semelparous: females produce one brood during the reproductive season, exhaust their energy reserves during incubation, and probably die at the end of the reproductive season, when the individual dry weight of the females is half the dry weight observed at the beginning of this season. Semelparity seems to be prevalent in species with extreme reproductive effort (Roff 1992) and in arthropod species that exhibit maternal care (Futami and Akimoto 2005 and references therein), as internal brooding.

In summary, E. braziliensis showed at the southern edge of its geographical distribution, a narrow reproductive cycle concentrated in austral summer. The high reproductive output and the internal retention of embryos could assure high offspring survival but not permitting females to reach the next reproductive season. The successful large-scale colonization and adaptation of $E$. braziliensis to the harsh reflective environment at its southern end of geographical distribution in the Atlantic Ocean appears to be facilitated through phenotypic reproductive plasticity. The narrow reproductive season of this peripheral population was counteracted by (1) a high representation of ovigerous females; (2) a short incubation period; (3) the highest individual sizes, fecundity, egg/embryo sizes and length at maturity documented for the species throughout its range; and (4) a high reproductive output. These extreme reproductive indicators at the edge of the distributional range could be attributed to specific characteristics of the life history of the species (ovoviviparity) as well as to a high adaptation capability to environmental variations across its range.

Acknowledgments This paper is part of the M.Sc. thesis of G.M. We are greatly indebted to Dr. M. Thiel for his constructive criticism, encouragement and support. Two anonymous referees provided useful comments that improved our manuscript. We wish to express our gratitude to the "Benthic Ecology Group" from UNDECIMAR and National Institute of Fisheries of Uruguay for field and laboratory assistance. G.M. especially thanks Roberto, Lía and Ximena. Financial support from CSIC, CONICYT (Projects $\mathrm{N}^{\circ} 1018$ and 4034), and PEDECIBA is acknowledged.

\section{References}

Bocanegra CA, Oliva J (1987) Biología reproductiva de Excirolana braziliensis (Isopoda). Rebiol (Peru) 6:31-42
Bocanegra CA, Oliva J, Avila C (1986) Distribución intertidal y densidad poblacional de Excirolana braziliensis (Isopoda) en las playas arenosas de Trujillo. Rebiol (Peru) 6:3-13

Brown JH, Stevens GC, Kaufman DM (1996) The geographic range: size, shape, boundaries, and internal structure. Ann Rev Ecol Syst 27:597-623

Caetano CHS, Cardoso RS, Veloso VG, Silva ES (2006) Population biology and secondary production of Excirolana braziliensis (Isopoda: Cirolanidae) in two Brazilian sandy beaches with different morphodynamics. J Coast Res (in press)

Cardoso RS, Defeo O (2003) Geographical patterns in reproductive biology of the Pan-American sandy beach isopod Excirolana braziliensis. Mar Biol 143:573-581

Carter RN, Prince SD (1981) Epidemic models used to explain biogeographical distributions limits. Nature 293:644-645

Charmantier G, Charmantier-Daures M (1994) Ontogeny of osmoregulation and salinity tolerance in the isopod crustacean Sphaeroma serratum. Mar Ecol Prog Ser 114:93-102

Croaker RA (1967) Niche diversity in five sympatric species of intertidal amphipods (Crustacea: Haustoridae). Ecol Monogr 49:746-751

Dahl E (1952) Some aspects of the ecology and zonation of the fauna on sandy beaches. Oikos 4:1-27

Defeo O (1998) Testing hypotheses on recruitment, growth and mortality in exploited bivalves: an experimental perspective. Can Spec Publ Fish Aquat Sci 125:257-264

Defeo O, Cardoso RS (2004) Latitudinal patterns and life history traits of the mole crab Emerita brasiliensis on South America sandy beaches. Divers Distrib 10:89-98

Defeo O, Martínez G (2003) The habitat harshness hypothesis revisited: life history of the isopod Excirolana braziliensis in sandy beaches with contrasting morphodynamics. J Mar Biol Assoc UK 83:331-340

Defeo O, Jaramillo E, Lyonnet A (1992) Community structure and intertidal zonation of the macrofauna in the Atlantic coast of Uruguay. J Coast Res 8:830-839

Defeo O, Brazeiro A, de Alava A, Riestra G (1997) Is sandy beach macrofauna only physically controlled? Role of substrate and competition in isopods. Estuar Coast Shelf Sci 45:453-462

Dexter DM (1977) Natural history of the Pan-American sand beach isopod Excirolana braziliensis (Crustacea: Malacostraca). J Zool London 183:103-109

Dworschak P (1988) The biology of Upogebia pusilla (Petagna) (Decapoda, Thallassinidea). III. Growth and production. Mar Ecol 9:51-77

Fernández M, Bock C, Pörtner HO (2000) The cost of being a caring mother: the ignored factor in the reproduction of marine invertebrates. Ecol Lett 3:487-494

Fish S (1970) The biology of Eurydice pulchra (Crustacea: Isopoda). J Mar Biol Assoc UK 50:753-768

Fonseca DB, Veloso VG, Cardoso RS (2000) Growth, mortality and reproduction of Excirolana braziliensis Richardson, 1912 (Isopoda: Cirolanidae) on the Prainha Beach, Rio de Janeiro, Brazil. Crustaceana 73:535-545

Futami K, Akimoto S (2005) Facultative second oviposition as an adaptation to egg loss in a semelparous crab spider. Ethology 111:1126-1138

Gilman S (2005) A test of Brown's principle in the intertidal limpet Collisella scabra (Gould, 1846). J Biogeogr 32:15831589

Glynn PW, Dexter DM, Bowman TE (1975) Excirolana braziliensis, a Pan-American sand beach isopod: taxonomic status, zonation and distribution. J Zool London 175:509521 
Harper JL, Ogden J (1970) The reproductive strategies of higher plants. I. The concept of strategy with special reference to Senecio vulgaris. J Ecol 58:681-698

Hoffman AA, Blows MW (1994) Species borders: ecological and evolutionary perspectives. Trends Ecol Evol 9:223-227

Johnson WS, Stevens M, Watling L (2001) Reproduction and development of marine peracaridans. Adv Mar Biol 39:105260

Kark S, Lens S, Van Dongen S, Schmidt E (2004) Asymmetry patterns across the distribution range: does the species matter? Biol J Linn Soc 81:313-324

Klapow LA (1970) Ovoviviparity in the genus Excirolana (Crustacea: Isopoda). J Zool London 162:359-369

Lardies MA, Cotoras IS, Bozinovic F (2004) The energetics of reproduction and parental care in the terrestrial isopod Porcellio laevis. J Insect Physiol 50:1127-1135

López L, Jeri T, González G, Rodríguez S (1997) Fecundidad y esfuerzo reproductivo de Petrolishes granulosus (Guerín, 1835) en Iquique, Chile (Decapoda, Anomura, Porcellanidae). Invest Mar Valparaíso (Chile) 25:159-165

Lozoya JP, Defeo O (2006) Effects of a freshwater canal discharge on an ovoviviparous isopod in an exposed sandy beach. Mar Freshw Res (in press)

Roff DA (1992) The evolution of life histories. Theory and analysis. Routledge, Chapman \& Hall, New York
Sagarin RD, Gaines SD (2002a) The "abundance centre" distribution: to what extent is it a biogeographical rule? Ecol Lett 5:137-147

Sagarin RD, Gaines SD (2002b) Geographical abundance distributions of coastal invertebrates: using one-dimensional ranges to test biogeographic hypotheses. J Biogeogr 29:985997

Stearns SC (1976) Life history tactics: a review of the ideas. Quart Rev Biol 51:3-46

Stella V, López L, Rodríguez E (1996) Reproductive parameters in the estuarine crab Chasmagnatus granulata (Decapoda, Brachyura, Grapside). Crustaceana 69:306-312

Thiel M (2003) Extended parental care in crustaceans-an update. Rev Chil Hist Nat 76:205-218

Weinberg JR, Starczak VR (1988) Morphological differences and low dispersal between local populations of the tropical beach isopod, Excirolana braziliensis. Bull Mar Sci 42:296309

Weinberg JR, Starczak VR (1989) Morphological divergence of the Eastern Pacific and Caribbean isopods: effects of a land barrier and the Panama Canal. Mar Biol 103:143-152

Zar JH (1999) Biostatistical analysis. Prentice-Hall, New Jersey

Zúñiga OR, Peña RM, Clarcke MG (1985) Excirolana braziliensis Richardson, 1912 (Isopoda: Cirolanidae) life history and production. Estud Oceanol (Chile) 4:9-19 